\title{
Estetización y autonomía estratégica
}

\author{
FRANCISCA PÉREZ CARREÑO \\ Universidad de Murcia
}

Soy partidario de la no violencia y la anarquía.

No admiro a Hitler ni a Stalin, pero sí a Bin Laden por querer hacer salir a EEUU de su terrible política internacional (Raymond Pettibon) $)^{2}$.

AUNQUE SON DIVERSOS LOS FENÓMENOS englobados bajo el término de «estetización» todos ellos son posibles en una atmósfera general de disolución de las fronteras entre lo que se suele llamar el arte y la vida: entre el arte elevado y el arte de masas, el arte elevado y el diseño o la publicidad, o la tecnología, etc. Entre esos fenómenos se ha prestado especial atención al que consiste en incorporar a la institución arte, y en particular al medio museístico, objetos de origen extraartístico que pasan a ser tratados como «obras de arte», y por tanto, y aunque no por necesidad teórica, atendidos básicamente como objetos de contemplación estética. Objetos que fueron producidos en otros ámbitos vitales, quizá religiosos o simplemente prácticos sin intencionalidad artística, son observados y tratados o considerados bien como obras de arte bien en relación a obras de arte.

En lo que sigue entiendo por estetización este proceso de institucionalización de ciertos objetos de origen no artístico que resulta en la consideración de

1 Este trabajo es resultado de la investigación financiada por el MEC(HUM2005-02533) y la Fundación Séneca (03089/PHCS/05). Un primer borrador fue presentado en el II Workshop sobre Experiencia Estética: Estetización, Neutralización, Depotenciación, celebrado en Barcelona entre los días 29 de noviembre al 1 de diciembre de 2007. Agradezco a todos los participantes la discusión de mi propuesta.

2 Raymon Pettibon, entrevista con motivo de su exposición retrospectiva «Raymond Pettibon, plots laid thick», en el MACBA, en El Mundo, 8-2-2002. 
estos como obras de arte, con indiferencia del proceso de producción que les dio origen, esto es, de su intencionalidad y sus medios de realización. Al menos desde algunas concepciones de arte hablar de origen extraartístico del objeto sea demasiado exigente, pero en todo caso, por origen no artístico entiendo que provienen de una actividad que no está intencionalmente guiada ni, primero, por el conocimiento de qué sea arte ni, segundo, por el dominio de los medios para producirlo. Estos dos criterios reproducen en negativo las condiciones que según la Teoría Institucional ${ }^{3}$ reúne el artista, es decir, la persona o las personas que participan con entendimiento en la producción de una obra de arte, es decir, de un objeto del tipo de los que son mostrados ante un público artístico ${ }^{4}$.

Especial mención requieren aquellos artistas que perteneciendo al mundo del arte, utilizan procedimientos, imágenes, o acciones provenientes de otros ámbitos, o los mimetizan con la intención de crear obras de arte. Por supuesto, es indiferente que ellos consideren explícitamente que su actividad lo es, simplemente la enmarcan en la institución artística, y adoptan el papel que en ese contexto les convierte en artistas. En este sentido, no es necesario el dominio del medio o el conocimiento de la actividad de la que proceden, sea por ejemplo, el comic, el video o la publicidad, sino los procedimientos de la institución artística. En una aplicación generosa de la teoría institucional, se trataría de artistas, puesto que crean o seleccionan y presentan un objeto ante el público artístico. Insisto en que la intención concreta que guía la presentación de ese preciso objeto, es decir, su sentido particular, no tiene porque ser estético, podría ser político, o político y estético, expresivo o simbólico, conceptual o formal, etc... O no tener ninguna intencionalidad concreta clara más que repetir el gesto del arte. Puesto que el origen del objeto es extraartístico lo que se produce es su institucionalización. Por institucionalización entiendo aquí la utilización de galerías, museos, exposiciones, de la actividad curatorial y crítica, y de la del propio artista para la consideración artística de ciertos objetos extraartísticos.

He dicho que se trata de una aplicación generosa de la Teoría Institucional porque lo que ella describe es la producción (o selección) de ciertos objetos con el trasfondo del mundo del arte. Es decir, que es el propio acto de producción del objeto artístico lo que es institucional, mientras que la institucionalización consistiría en la posterior colocación de un objeto cualquiera en un contexto artístico concreto de presentación.

3 Cfr. G. Dickie, El círculo del arte, Barcelona, Paidós, 2005. [The Art Circle, Nueva York, Haven, 1997.]

4 Elijo la Teoría Institucional porque es precisamente la que no incluye ningún criterio sobre qué deba ser, qué aspecto deba tener, qué medio utilizar, o que función cumplir, una obra de arte. Cfr. G. Dickie, op.cit. 
Antes de continuar contestaré a una crítica posible de la distinción anterior, crucial para mi argumentación, entre origen institucional e institucionalización del objeto. La crítica señalaría a la existencia del ready-made como forma artística reconocida, que parece en principio ser un caso de institucionalización, la selección y presentación de un objeto extraartístico ante un público del arte. No pretendo hacer del ready-made un caso central de ninguna teoría artística, sino al contrario, mantenerlo en el lugar marginal que le da su significado y su valor. Este lugar liminal hace posible que se convierta en una puerta hacia la institucionalización, como señaló Peter Bürger, al diferenciar entre los ready-made dadaístas de los neovanguardistas. Según Bürger, al que sigo en el análisis aunque no en la generalizada condena de la neovanguardia, la diferencia crucial es que la obra de Duchamp, por ejemplo, tenía un contenido anti-institucional del que carecían sus repeticiones neovanguardistas. El gesto antiinstitucional de Duchamp tenía sentido contra el trasfondo de una institución artística que iba a percibir el objeto como una provocación, como una crítica radical a las convenciones que la sostenían. Es decir, era arte porque estaba realizado como un objeto artístico más para ser presentado ante un público del arte. Otra cosa es que se tratara de una acción que criticaba profundas convenciones de la propia institución artística. La institución aguantó, pero la crítica de Duchamp sigue teniendo sentido ${ }^{5}$. Ahora bien, una vez que la institución los reconoce como artísticos, los objetos ready-made carecen de sentido como críticas de la institución. Son obras de arte en el mismo sentido que los ready-made dadaístas, pero carecen de su fuerza antiinstitucional. El caso límite es el de Duchamp que tensa al límite la institución para criticarla, pero aún así lo hace precisamente dentro de su marco.

Así pues, mientras que la producción artística es institucional en el sentido de que el artista crea su objeto con el trasfondo de la institución, lo que da sentido a su acción, la institucionalización consiste no en la creación de un objeto sino en la introducción en el mundo del arte de objetos de otra procedencia. De esta forma la institucionalización hace posible el trato como arte de objetos que no proceden de la institución, pero, ¿con qué fin? ¿cuál es su sentido? El resultado más evidente del trato artístico es la consideración del objeto como autónomo, esto es, como evaluable bajo parámetros que no son los propios de la actividad en la que se ha producido, pero, sobre todo, como perteneciente a una esfera de la actividad humana inmune a la crítica científica o política,

5 La acción de Duchamp era institucional con un contenido antiinstitucional; igual que las metáforas que servían de título a sus obras presentaba una objeto que no podía ser entendido literalmente sino que exigía una interpretación metafórica. 
teórica o práctica en general. Es decir, el objeto se autonomiza o estetiza ${ }^{6}$ en el sentido de que pasa a ser objeto de protección de la Estética.

Este proceso de estetización es habitual en el mundo del arte actual, que paradójicamente pretende poner en evidencia la autonomía del arte moderno. Sin embargo, el rechazo teórico de la concepción autónoma del arte ha ido acompañado de una estetización paralela, externa, realizada por las instituciones, y que esconde pretensiones de autonomía como nunca se habían conocido. Según mi idea, la pretensión o la falsa conciencia consiste en creer y en hacer creer que se está produciendo un arte heterónomo, que rompe el aislamiento del arte y sus pretensiones de autonomía, que está ligado a la vida social, que tiene intencionalidad política o ética, y que es heredero de este impulso vanguardista, cuando realmente no hay una crítica independiente y severa que señale sus debilidades y cuando se utiliza continuamente al museo como puerto franco, y se concibe el arte como el ámbito en el que casi todo está permitido. En realidad se producen dos situaciones indeseables para el artista crítico: o bien su acción queda circunscrita al ámbito del museo y a un menguado público artístico, no alcanzando a todo el potencial público artístico, a la sociedad en su conjunto, o bien, puesto que el museo se ha masificado, el artista es observado como un animal salvaje en el zoo, en el ámbito del entretenimiento y la industria turística.

Es una idea comúnmente admitida por la estética postmoderna y los Estudios Culturales, que la consideración estética de un artefacto neutraliza, descarga de fuerza semántica y pragmática los objetos provenientes de ámbitos no artísticos (de otras culturas, prácticas, clases, géneros, etc...). Al presentarlos en el contexto artístico, habitualmente el museo, la galería o la feria, los objetos son en primera instancia contenido de asombro, contemplación e interrogación estética, lo que puede implicar evidentemente la depotenciación del objeto considerado. Por ejemplo, Moxey afirma: «...el poder de esta idea ha permitido que los artefactos del mundo sean coleccionados y apreciados bajo la rúbrica de «arte», también ha tendido a borrar la cualidad que los hizo fascinantes en su origen» ${ }^{7}$. Es curioso cómo se traslada la fascinación que el

6 Agradezco a Jordi Ibáñez que me exigiera la diferenciación entre artistificación y estetización. Que un objeto extraartístico sea introducido en el mundo del arte solo significa que se artistifica, pero cuando este proceso conduce a su «aforamiento» artístico, entonces se estetiza. Odio utilizar la palabra «estética» en este sentido, que por otra parte es usual.

7 M. Cheetham, M.A. Holly y K. Moxey, «Estudios visuales, Historiografía y Estética», Estudios visuales, 3, 2006, p. 20. En términos políticos de antiglobalización se expresa McEvilley sobre la exposición artística de objetos del «Tercer Mundo»: «...los objetos expuestos que en su 
miembro de la institución siente a una presunta fascinación del objeto en origen, que bien pudiera no existir.

Ahora bien, la institucionalización no es solo un instrumento debilitador sino que también puede ser fortalecedor. Potenciación o despotenciación son efectos que no se siguen de la contemplación estético-artística de un objeto, sino de la intención con que este objeto espera ser tratado. Igual que un muro aísla y protege según como se utilice, de la misma manera, la estetización de un objeto supone prestar atención a propiedades que eran con anterioridad insignificantes o que ni siquiera existían y que dependen de la relación que se establezca en la interpretación, entre ese objeto y otros. Por ejemplo, desde el punto de vista de la magia se depotencia el objeto religioso que se muestra en una exposición, pero desde un posible punto de vista estético, se explotan sus semejanzas con objetos que en una cultura laica tienen mayor valor. Considerar lo estético o lo autónomo dogmáticamente, sin atender a su dependencia relativa del contexto social e histórico, es claramente erróneo e insuficiente, con independencia del poder que lo estético pueda tener en sí mismo.

Presto atención en adelante a este mecanismo de robustecimiento a través de la estetización, que se produce en dos sentidos:

En primer lugar, la estetización institucional, al introducir, entronizar ciertos artefactos en las instituciones del mundo del arte les presta el reconocimiento social del que anteriormente carecen: atención, prestigio, dinero... Y lo que más me interesa para lo que sigue, la institución le presta protección frente a la crítica. Se podría objetar que la forma de considerar un objeto como arte consiste precisamente en tomarlo como objeto de crítica, y que la crítica podría / debería ser suficiente para que dado el caso de su falta de valor perdiera sus privilegios y quizá su estatuto. Ahora bien, esto solo sucede cuando la crítica es independiente, o cuando su autoridad se refiere no solo a las cuestiones «estéticas» sino a todas aquellas que constituyen el objeto como tal.

La institucionalización de objetos extraartísicos conduce a un movimiento de autoría a la que no me he referido antes. El responsable de la institucionalización, director del museo, comisario de la muestra, etc., se convierte en quien presenta el objeto ante el público del arte, y quien es responsable, por tanto, de su significado y su valor. Esto le convertiría en artista de la exposición en su conjunto y el responsable de la estetización de los artefactos presentados. La crítica lo sería no del objeto sino de la exposición en su conjunto. Naturalmente

contexto original solían ser fetiches religiosos, se convierten por el contrario en los fetiches de la religión profana del imperialismo, al que simbólicamente justifica por el hecho de que se fuerza a dichos objetos al sometimiento», «Abrir la trampa. La exposición posmoderna y Magos de la Tierra», en A. M. Guasch, (ed.), Los manifiestos del arte posmoderno. Textos de exposiciones, 1980-1995, Madrid, Akal, 2000, p. 362. 
esto sucede también con la exposición de objetos que ya eran artísticos en origen, pero en este caso, es posible apreciar el objeto como objeto artístico en sí mismo, mientras que en el caso anterior no lo es. O bien, se llama la atención sobre él mismo gracias a su situación institucional, o bien permanece en la situación originaria, fuera de los focos del mundo del arte. Foster analizó el problema en «El artista como etnógrafo» en el caso concreto de proyectos site-especific, consistentes en el mapping de prácticas, espacios, o comunidades ajenos al mundo del arte para su exposición artística. Según Foster, en estos casos «la institución oscurece la obra que por otro lado ilumina: se convierte en espectáculo, atrae al capital cultural y el director-comisario se convierte en estrella» ${ }^{8}$.

En segundo lugar, y como consecuencia de lo anterior, la institucionalización provoca la estetización de la experiencia que el artefacto exige. La institucionalización se requiere o se justifica porque favorece o incluso hace posible la atención centrada en el objeto y en sus cualidades sensibles, formales o técnicas, lo que estetiza la experiencia. También lo hace cuando no se trata de objetos, sino de documentos, acciones, proyectos in situ, que se convierten en casos de curiosidad etnográfica, en el mejor de los casos, sin que se llegue a hacer un verdadero análisis etnográfico. Lo que parece evidente es que la institucionalización garantiza la atención a productos, situaciones, contextos no artísticos, sin que sea necesario un verdadero interés o estudio de la situación originaria y sin que, como consecuencia, cambie necesariamente la relación del espectador con la práctica vital.

Está claro que en los dos aspectos se mantiene la autonomía en sentido moderno de lo artístico. Aunque aparentemente el artista postmoderno renuncie a la autonomía inmanente, es decir, cree obras con contenido social y con intención política evidente, no puede renunciar a la autonomía social, que se concreta en su propia libertad, y en la especificidad de los ámbitos en que se expone, interpreta y critica su trabajo. (Y que puede ser compatible si no con la «absoluta falta de libertad de la totalidad» como decía Adorno, sí con la falta de libertad de muchos). La autonomía interna, o que le es «inherente» a lo artístico, se concreta en la emancipación de los medios expresivos y de las reglas de producción de sentido. Del modo más interesante, no como expresión del talento individual, sino como desarrollo histórico de la actividad producto de la misma crítica interna. Pero una vez que no hay medios específicos de crítica, la crítica interna solo podría ser crítica política y esta resulta incapaz frente a la autonomía institucional.

8 H. Foster, «The artist as ethnographer», en: The Return of the Real. Avantgarde at the end of the Century, Cambridge: The MIT Press, 1999, p. 198. [La traducción es mía]. Foster propone evitar estos problemas convirtiendo al artista etnógrafo en objeto de reflexión sobre su propia situación, y por tanto también en contenido de la obra. 
A partir de los años sesenta la disolución de las barreras entre los medios y la superación de esta narrativa moderna que liga autonomía y desarrollo de las artes da paso a una situación en la que la crítica de la obra de arte no puede basarse en los antiguos criterios. En un sentido, la autonomía del arte en sentido interno es imposible cuando no hay medios específicos en los que la expresión o el principio constructivo se pueda desarrollar. No por el valor del medio en sí mismo sino como configurador de una experiencia que se concibe de muy diversas maneras pero que es identificada como «estética» y que se caracteriza por una específica capacidad de convencimiento, de fuerza retórica de la obra sobre el espectador. En el núcleo del paradigma abandonado, moderno, residían la autonomía y la teoría estética que la justificaba.

En la situación actual la teoría estética no es válida porque, se dice, el aspecto de una obra de arte y de un objeto normal y corriente puede ser el mismo. O bien, porque el desarrollo hasta la hipertrofia de los principios formales en el arte de vanguardia ha desembocado en ideología, es decir, en la ocultación de la verdadera naturaleza burguesa del arte, de su heteronomía respecto al capitalismo, el colonialismo, la globalización, etc., y en su carácter al servicio de estos. Evidentemente la autonomía del arte y su soberanía, residía en su poder para imponerse retóricamente sobre la sensibilidad y la mente del espectador. Y ese poder es para bien y para mal.

Buena parte del arte producido actualmente no puede ser sino «regresivo» desde los presupuestos modernos. En el sentido de que recurre a o recupera los elementos miméticos eliminados en el arte anterior: por supuesto a la figuración, las imágenes y los contenidos de la cultura de masas, o de todo tipo de origen, y el carácter ritual o mágico de la representación, desde el body art al llamado por Danto Disturbation Art, o a los trabajos «etnográficos», documentales o de proyectos de acción específicos. Sin embargo, también la estrategia de la vanguardia actual o la neovanguardia no puede ser sino regresiva desde los presupuestos vanguardistas, en el sentido de que la pretendida crítica de la autonomía y la buscada «fusión del arte y la vida» se hace incorporando contenidos «transgresores» o representaciones extra artísticas con esos contenidos a la institución arte, es decir, institucionalizándolos, nutriendo a la propia institución que quiere criticar. Por seguro que el artista se sienta del valor de ese contenido como tal y de su deber crítico, la autonomía institucional solo garantiza la existencia y el público, pero no la influencia que es específica del arte. En demasiadas ocasiones el arte contemporáneo ha renunciado a la autonomía inmanente sin renunciar a la autonomía institucional y eso no puede resultar gratis.

Una vez que el contenido de la obra y su intencionalidad se hacen evidentes no queda ninguna marca del carácter artístico del gesto. Lo cual puede no 
ser ningún demérito. No lo sería en absoluto, además. Ni siquiera cuando se tratara de propaganda. Ni siquiera cuando se tratara de propaganda con pretensiones estéticas. El problema es que normalmente no se quiere / no se puede renunciar a los beneficios que el carácter autónomo ofrecía a los artistas. De tal manera que se busca la forma de «poner entre paréntesis» una representación que por otro lado puede ser idéntica a una representación que no lo necesita porque pertenece al mundo de las prácticas reales. El arte conceptual o el arte surgido del fotoperiodismo, por ejemplo, en el que supuestamente se evitan las connotaciones estéticas, conduce a la «paradoja de Eurípides» ${ }^{9}$ de la misma manera que el arte mimético, esto es, diluyendo la frontera que lo convertía en arte, y que permitía y exigía que su interpretación fuera diferente, y que sus propiedades se transfiguraran ante los ojos de los espectadores. Cuanto menos diferencia exhiben con representaciones no artísticas, menos razones existen para prestarles una atención específica. Ahora bien, si no se quiere una interpretación específica de la representación, si no se quieren ver transfiguradas las propiedades del objeto, es decir, si se quiere que la representación no sea artística, entonces cualquier estrategia de puesta entre paréntesis es externa y, según mi punto de vista, estetización institucional.

La estetización se produce mediante el ingreso en el museo, en el contexto del arte, es decir, mediante su institucionalización. De esta manera, al contrario que su depotenciación, se produce su robustecimiento. Las obras que así adquieren su estatuto requieren para sí la consideración de aquellas obras que estaban en un contexto autónomo porque habían sido producidas de forma autónoma. Que se muestren en el contexto institucional es absolutamente imprescindible para el desarrollo de la actividad, para el logro de aquello que se persigue, cuya justificación queda entonces al margen de cualquier juicio claro. Naturalmente el hecho de que el marco de la autonomía institucional permita no solo mayor libertad del artista sino que además favorezca el alcance de la respuesta del público y su actitud favorable es algo que no pasa desapercibido a los defensores de la Vanguardia. Foster habla en este sentido de «autonomía estratégica» ${ }^{10}$. Adoptar las ventajas que ofrece la institución, sin creer en la justificación de la existencia de tal institución, sino más bien conociendo su carácter político al servicio de aquello que suponen el arte debe combatir.

La autonomía de la institución arte es deseable en el sentido de que garantiza el desarrollo de la propia actividad artística, y se convierte en nada si esta

9 Cuanto más naturalista es una representación más posible es que pase desapercibida, confundida con la vida, y más necesario es que se señale, externamente, su existencia. $C f r$. A. Danto, La transfiguración del lugar común, Barcelona: Paidós, 2002, pp. 53 y ss.

10 «Polemics, Postmodernism, Immersion, Utilitarizaed Space», Journal of Visual Culture 3(3): pp. 320-35. 
actividad no está sujeta a una crítica rigurosa. La razón es que la autonomía institucional se justifica por el valor de lo que se produce en su seno. Y hablo de autonomía en un sentido muy amplio en el que cabe la tolerancia con las imprecisiones, ambigüedades, modas y snobismos que parecen inseparables del mundo del arte. Todo ello es tolerable si lo que resulta es, en general, valioso. Igual que las instituciones científicas, por no decir filosóficas, necesitan esa autonomía, con independencia de que un determinado experimento sea ruinoso o una determinada teoría infumable ${ }^{11}$.

Finalmente la autonomía inmanente de las obras de arte es solo relativa, puesto que su producción, su medio, sus contenidos y las respuestas que provocan son sociales. Ahora bien, la autonomía entendida como especificidad de lo artístico, de la historia interna de la actividad, de la crítica que le es propia, es irrenunciable si se quiere justificar la autonomía institucional. Sin duda lo primero que es preciso es que la crítica reconozca que el poder del arte reside precisamente en su carácter no autónomo, sino en relación a procesos empíricos concretos. Y que la crítica se refiera, señale, clarifique, o desvele en cada caso cómo se produce.

En algunos casos la estetización debida a la institucionalización no solo resulta en una depotenciación o robustecimiento de los objetos institucionalizados sino que son motivo de su utilización inmoral. Los dos casos que siguen me parece que ejemplifican esta situación de utilización de la excusa política de una forma contradictoria con la propia intención declarada.

\section{IV}

Las fotografías procedentes de los archivos del Museo del Genocidio de Tuol Sleng, en Phnom Pehn, Camboya, que representan algunas de las más de 16.000 personas ejecutadas allí entre 1975 y 1979 por el régimen de los Jemeres Rojos, son un escandaloso ejemplo de estetización de un documento del genocidio. Setenta y ocho de estas fotografías fueron impresas en el libro The Killing Fields (1996), expuestas al menos en un festival de fotografía (en Arles, 1999), y compradas y expuestas por algunos MoMA ${ }^{12}$. El de Nueva York las expuso como Fotografías de $S$-21, el nombre del aula de la escuela donde

11 Agradezco en este punto la discusión entre y con Matilde Carrasco y Jordi Ibáñez sobre el arte como «especie protegida». Como filósofos debemos en principio simpatizar con la idea de la protección de especies en peligro. La autonomía institucional del arte es un valioso escudo protector en las sociedades totalitarias, no así en las democráticas, en las que no añade nada nuevo a la libertad de expresión.

12 Es distinto el caso del film S-21. The Khmer Rouge Killing Machine, de Rithy Panh, 2002. Agradezco a Mikel Iriondo esta precisión. 
fueron tomadas. Aparentemente este hecho es posible porque estamos en una situación postestética en la que presuntamente no son las cualidades estéticas las que hacen de un artefacto una obra de arte, sino en este caso, por ejemplo, su interés político y ético. Yo creo que justamente lo contrario es el caso y que la estetización generalizada ha alcanzado de lleno al arte político.

Una de las reseñas de The Killing Fields expone: «Los rostros expresan miedo, tristeza, fatalismo, valientes intentos de sonrisa, e incluso ira sospechosa. Usualmente, bajo el rostro hay un número pinchado en una camisa; te puedes ver a ti mismo mirando fijamente al torso desnudo de un preadolescente para asegurarte de que el letrero está pegado a la piel y no pinchado en ella, de alguna manera insangrienta, (tan brutales son las fotos que el sadismo es previsible). Por supuesto que también hay belleza en esos rostros, lo que no los salvó de la ideología revolucionaria» ${ }^{13}$. El autor de la crítica, Ray Olson describe adecuadamente el impacto que las fotos producen en el espectador, la curiosidad que puede llegar a sadismo, las respuestas previsibles al miedo y la tristeza: la compasión, la admiración, la indignación... Las respuestas a la belleza, la juventud, la vejez o la indefensión de los retratados. Se trata de respuestas a varios factores, en primer lugar al contenido icónico, es decir, a la percepción de rostros expresivos, de cuerpos de carne y hueso; en segundo lugar, al conocimiento del destino de los fotografiados.

La tortura a la que se sometía a las víctimas de S-21, incluía un acto más de humillación como era el de la fotografía para el registro. Del resto de las terribles humillaciones no somos testigos, sino que tenemos testimonios. Pero de esta somos testigos y, por tanto, sujetos de culpa y de vergüenza. Esas fotografías, seleccionadas entre miles por los fotógrafos americanos Chris Riley y Douglas Niven por su calidad fotográfica y su capacidad expresiva, son impresas y vistas por millones de personas en todo el mundo; robadas a los dueños de su imagen, las víctimas son exhibidas impúdicamente y su tortura revivida póstumamente.

Años después, Christian Caujolle, el comisario de los Rencontres photographiques d'Arles de 1997, vuelve a exponer las fotos en ese contexto. El ámbito del fotoperiodismo es particularmente sensible a los deslizamientos entre arte y no artístico, y por eso, previsiblemente utilizado por artistas para tratar de salvar la distancia entre el arte y la vida, y redimir al arte de su culpable autonomía. Estoy de acuerdo con las apreciaciones de De Duve sobre la naturaleza de la fotografía y sobre la confusión actual y los «deslizamientos» entre fotoperiodismo y fotografía artística en su ensayo sobre las fotografías de S-2 $1^{14}$. En una exhibición fotográfica se pueden dar cita fotografías artís-

13 Ray Olson, Bookslist.[La traducción es mía].

14 T. De Duve, «Art facing the radical evil» en: http://www.sanart.org.tr/congresses/ICA/plenaries/DeDuveT.pdf 
ticas de carácter documental, fotografías de aficionados, de artistas, imágenes de fotoperiodistas sin intencionalidad artística, seleccionadas por sus autores o por otros, etc... Estoy de acuerdo, en que es precisamente la represión del reconocimiento de que en el núcleo de las decisiones políticas en el terreno del arte hay cuestiones estéticas, lo que impele a sobreactuar a los responsables en la justificación de estas decisiones.

Caujolle no puede reconocer que expone las fotografías por razones «estéticas» (o por el impacto que le produjeron), o por razones «artísticas» (por ejemplo, por el dominio del medio mostrado por su autor, que lo convertiría en artista), y aduce razones éticas: «recordarnos que dos millones de personas, de una población de siete millones, había sido masacrada (en Camboya) y que nadie se inmutó» ${ }^{15}$. Su intención es exponerlas como «no arte», en un capítulo del festival titulado «The duty of memory» y trata, presuntamente, de desestetizarlas para que efectivamente no parezcan arte (lo que por otro lado es habitual en el arte contemporáneo). Sin embargo, finalmente las estetiza de nuevo: las expone esperando que produzcan en el espectador el impacto que produjeron en él, que es una mezcla de admiración estética y repulsión y rechazo de ese sentimiento, y las expone junto a fotografías de carácter claramente artístico, bien desde el punto de vista tradicional, bien desde el punto de vista del «izquierdismo académico» 16 .

El crítico de fotografía de Le Monde, Michel Guerrin, afirmó sobre las fotos de S-21: «...han adquirido un estatuto 'artístico' entrando en las colecciones de museos prestigiosos como los museos de arte moderno de Nueva York, San Francisco y Los Angeles» ${ }^{17}$. Guerrin admite que la mera exhibición en un museo las convierte en artísticas, cuando lo que hace es estetizarlas, precisamente aquello de lo que supuestamente huyen sus exhibidores, y los teóricos y críticos que justifican su exhibición. Parte de la cuestión es si realmente las imágenes no eran artísticas en origen, y quizá sí lo fueran, como argumenta De Duve. Desde su punto de vista, el problema estriba en asumir el prejuicio postmoderno de no admitir lo estético en la definición de artístico. Y, por tanto, en evitar enfrentarse al conflicto entre lo ético y lo estético. En evitar, por ejemplo, hablar de la fotografía como un arte (en el sentido estético) y asumir los problemas que conlleva su carácter indéxico. Si se admite que el fotógrafo del campo de tortura S-21, era un artista, porque hacía buenas fotos o porque, por ejemplo, abría un mundo (eso sí de crueldad extrema), entonces su lugar es

15 Declaraciones de Caujolle en Arles, el 7 de julio de 1997, en F. Docquiert, y F. Piron, (eds.), Image et Politique, Arles: Actes Sud, 1998, p. 104. Citado en: De T. Duve, loc. cit.

16 La expresión es de T. De Duve, loc. cit.

17 M. Guerrin, «La photographie documentaire surexposée», Le Monde, July 6, 1997. Citado en De Duve, T., loc.cit. 
el museo. Los que quedan fascinados cuando las descubren y tienen poder para exponerlas en instituciones artísticas tendrían que admitirlo, aunque después decidieran exponerlas. Que fuera un artista al tomar las fotos no implica que no estuviera a la vez participando en un acto de tortura.

No es este el punto de partida que hemos asumido al comienzo del texto, sino el de una definición institucional, que solo supone dos condiciones de la producción artística, el conocimiento de que se trata de arte y el dominio de los medios para producirlo. No parece que el fotógrafo de S-21 tuviera en mente estar realizando arte, sino más bien una tarea burocrática, más parecida a la de los fotógrafos policiales. Sin embargo, el tema no está cerrado. Incluso si este fotógrafo fuera un artista, estaría por decidir exponer o no su obra. Puede ser que el conflicto sea entre ética y estética. Al decidir exponer su obra el comisario que quiere y no quiere a la vez conservar el origen de la fotografía está evitando el problema. Decide exponerlas y quiere hacerlo sin pagar por ello.

De Duve puede estar en lo cierto en que solo entendiendo el museo (y el arte) de forma no humanista es posible que este tipo de obra adquiera el valor que merezca. Sin embargo no está claro que se trate de algo deseable y, en todo caso, lo cierto es que la filosofía no puede estipular qué sea el museo. Hoy por hoy, la concepción de grandes museos (y pequeños) es la de ser guardianes, cuidadores, exhibidores de los logros de la humanidad, y actúan, por tanto, prejuzgando y sancionando qué sea o no artístico y valioso desde ese punto de vista. Tanto da que el criterio sea formalista, o postmoderno, o vanguardista-revolucionario, o sin criterios claros. En este caso, si es que las fotos son en origen artísticas, lo cierto es que su exhibición museística es una posterior estetización, ofreciendo un pretexto institucional a su contemplación. De hecho, los responsables tratan de aliviar su mala conciencia con coartadas ideológicas.

Aunque De Duve no oculta, sino que señala evidencias a favor de que el autor pudiera considerarse un artista y de que la respuesta que producen las fotos sea estética, también utiliza un argumento que justifica la superación de la incomodidad que la contemplación de las fotos le producía. Y la encuentra en la propia naturaleza indéxica de la fotografía y en su calidad icónica, que le habría permitido reconocer en el rostro fotografiado la individualidad (la dignidad) de la persona que iba a morir, supuestamente más allá de un mero reconocimiento de una humanidad abstracta. Sin embargo, De Duve busca de nuevo justificarse ${ }^{18}$. No porque no fuera cierto que psicológicamente este argumento le tranquilizara, sino porque mínimamente se puede restaurar la individualidad a alguien a quien no se conoce en absoluto, del que no se imagina $s u$ miedo o $s u$ estado interior. Es cierto que el carácter, no ya indéxico, sino aurático de la fotografía del rostro, nos pone por su mirada mágicamente 
en contacto con quien estuvo allí. Pero debe seguir siendo insoportable para alguien que vive, como nosotros, mirar al humano del que sabemos que fue víctima de una terrible tortura. Esa es quizá la diferencia relevante y es la que resulta imposible superar estéticamente.

Si parte de la clave del valor del arte es retórica, si el efecto estético consiste en la fuerza con la que la obra de arte nos impone una visión de un objeto, esa fuerza es peligrosa por definición. Es para bien y es para mal. Lo que es ideológico es suponer que el museo limpie las manchas de origen, o que una vez en su ámbito el objeto haya ganado «autonomía», se haya liberado de esa intencionalidad retórica. No sé hasta qué punto sería menos problemático que las fotos fueran ficción. Pero en un punto lo sería menos: no estaríamos obviando la historia causal de la producción de la fotografía para juzgarla, su origen real, aunque los efectos en todo lo demás fueran los mismos. No estaríamos utilizando la imagen de alguien real que murió realmente, y que no es personaje, sino persona.

Otro ejemplo de institucionalización son las fotografías de Clemente Bernard en la exposición Chacun à son goût (Cada uno a su gusto), comisariada por Rosa Martínez, y que presenta una selección de artistas vascos contemporáneos que han realizado nuevos proyectos para celebrar el décimo aniversario del Museo Guggenheim de Bilbao. Basque Chronicles es una selección de imágenes relacionadas con violencia en el País Vasco que Clemente Bernard ha ido realizando desde 1989. Bernard es un fotoperiodista, que recibió en 1994 un premio FotoPress de los Derechos Humanos por su obra Mujeres sin tierra. Otra vez nos encontramos con el artista como etnógrafo del que hablaba Foster.

Bernard es fotoperiodista y artista. Y no parece que identifique ambas actividades, sino que él mismo hace ciertas distinciones. Por ejemplo, aunque su trabajo como fotoperiodista sea el de ilustrar noticias o de dar noticia de ciertos hechos o sucesos, por tanto, aunque su trabajo haya de ser veraz, Bernard ha escrito en diversas ocasiones sobre el hecho innegable de que las fotografías no tienen una relación directa con la verdad y el sentido: «(l)as fotografías son elocuentes y eficaces porque juegan hábilmente con la apariencia, con el tiempo, con la ambigüedad y con la confianza del lector, pero en realidad confunden y no prueban nada: no se puede confiar en ellas» ${ }^{19}$. Bernard afirma con razón que las fotos necesitan de contextualización para que se pueda establecer su

19 C. Bernard, «La trampa del fotoperiodismo», Capçalera. Texto completo en: http:// www.clementebernard.com 
relación con la verdad. Son el contexto histórico, las afirmaciones sobre los hechos, los discursos lingüísticos los que se la proporcionan.

La relación del arte con la verdad es de diferente tipo, quizá todavía más difícil de establecer, pero a Bernard no le preocupa: «Más allá de la fotografía periodística se abre otro mundo igual de convulso, donde también hay una batalla entre lo real y su representación, pero donde se admiten las licencias que el arte y la estética otorgan a los autores. Si lo que se pretende es crear un mundo simbólico a costa de manipular conscientemente aquello que sucede ante uno, no hay problema en abrir las puertas de las galerías o de los museos» ${ }^{20}$. Según una concepción más bien prepostmoderna y acrítica de artista, utiliza la ocasión para realizar una selección propia, autónoma, no guiada por el interés de la noticia, que ilustra una idea propia, y que pretende sobrevolar la historia de los momentos concretos para adoptar una mirada global más allá del sentido de la imagen en relación a un tiempo y un espacio reales. Bernard aprovecha la oportunidad que le da el Guggenheim y realiza un trabajo artístico diferente de su trabajo como fotoperiodista y que consiste en la «manipulación», en la elaboración de una narración gráfica a partir de aquellas imágenes tomadas como fotoperiodista.

Bernard se considera a sí mismo un fotoperiodista, aunque en esta ocasión lo que ha pretendido es presentar «su» punto de vista sobre el que denomina «conflicto vasco». Lo hace con imágenes de origen periodístico de cuya ambigüedad, y a pesar de ello, de cuyo poder, es consciente. Sobre la posibilidad de comunicar su punto de vista se trata en este caso, según Bernard, de crear en el espectador una empatía con el que sufre: «Cuando veo a un familiar acariciar el cadáver de su hermano, militante de ETA muerto, no me queda otro remedio que empatizar con esa historia porque son muertos en un acto de violencia de un conflicto oscuro y difícil de comprender, en ambos casos» ${ }^{21}$. La fotografía como un arte aspira a crear una experiencia en el espectador, una experiencia ajena a la del fotoperiodismo, que ha de ilustrar y proporcionar evidencias de un suceso. Este elemento retórico-estético de todo arte ha de nacer de los medios que le son propios y cuando se utilizan procedimientos externos estamos ante casos de espectacularización, de sentimentalización, o estetización. Bernard utiliza los tres: amplía las fotos, las selecciona y las coloca para producir un efecto buscado. Lo hace con toda conciencia y en contra de sus propias ideas sobre lo que es el fotoperiodismo -según un bien aprendido relativismo sobre su contenido informativo, pero no en contra de sus propias ideas sobre la fotografía como un arte, es decir, estetizada: en este caso el efecto ha de liberarse de la historia causal del la producción de la imagen y del contexto histórico en

20 «La imagen de la culpa», en C. Bernard, loc. cit.

21 Declaraciones en: Diario de Noticias de Navarra, 18 de noviembre de 2007. 
el que tiene sentido y encajarse en el proyecto del autor y en su discurso. En sus propias palabras: «....no habría que perder de vista en ningún momento que, si bien no hay límite alguno tras las puertas de las galerías de arte para que cada cual dé rienda suelta a su creatividad, el fotoperiodismo no es evidentemente el lugar de la manipulación. El arte no tiene por qué cargar con ningún tipo de responsabilidad. Pero el periodismo sí» 22 .

Las asociaciones de víctimas de ETA han denunciado el que consideran un punto de vista «equidistante», que iguala a las víctimas, que lo son no unas de otras, sino de un «conflicto vasco» cuyo responsable es el «Estado Español», presente en la exposición en una foto con militares golpistas. No me interesa tanto repetirlo aquí como señalar cómo el discurso se impone estéticamente: naturalizando el discurso político al utilizar las imágenes para crear compasión (él dice empatía) con el que sufre. Las asociaciones de víctimas dicen que «iguala a los muertos» y efectivamente lo hace explícitamente. Intenta trazar el camino inverso al que De Duve intentaba caminar frente a las víctimas del régimen de Pol Pot. En lugar de individualizarlas, las iguala. No distingue entre víctimas inocentes y víctimas que murieron manipulando un explosivo, que por lo tanto no son inocentes. Y las hace a todas víctimas del fascismo, aunque hayan muerto o muerto matando en la España democrática.

Porque las fotografías se exponen en un museo y son seleccionadas sin más cortapisas que la libertad del autor, el fotógrafo se convierte en «artista» y la estetización es doble. El Guggenheim lo sanciona como un discurso valioso, le proporciona un marco de seguridad y reconocimiento, emancipándolo, por ejemplo, del discurso político, y Bernard lo utiliza para emancipar a sus fotos del contexto periodístico, histórico, empírico, dándoles el sentido que prefiera.

Ahora bien, aún despojándolas del contexto concreto, que en todo caso el público conoce, las imágenes guardan la relación indéxica con los objetos representados y con una situación concreta. De hecho, Bernard justifica su trabajo por su solvencia como fotoperiodista, su interés por la situación y por las buenas intenciones que lo guían. Necesita una justificación ideológica porque la libertad del artista tiene aquí unos límites más precisos que de costumbre. Una vez que la referencia de la narración es real, lo que se diga de ella o lo que se insinúe, puede ser verdad o mentira, vacuo o significativo, ideológico o desmitificador, se diga en un periódico, en el taller de un artista o en las salas de un museo. La autonomía estratégica proporcionada por el museo no debe ser un escudo frente a las críticas, provengan de donde provengan, máxime una vez que se ha puesto en tela de juicio desde el carácter veraz de la fotografía al carácter humanista del museo. Por eso han de aplicarse a Bernard las mismas reflexiones que él utilizaba para referirse a la exposición Signos del 
arte vasco actual que a finales de 2006 financiaba Coca-Cola en la Fundación Bilbao Arte: «Muchas de las grandes obras de arte se han hecho a la sombra de mecenas que encarnaban el poder económico, político o religioso -cuando no todos al mismo tiempo-, pero también es necesario observar ciertas reglas de comportamiento, de protocolo, de buenas maneras. Que los lobos se vistan con piel de cordero es un clásico en las relaciones humanas y muestra uno de los muchos puntos débiles del discurso del arte contemporáneo, que se siente capaz de elaborar cualquier andamiaje para cualquier obra, seguramente porque no encuentra resistencia alguna a sus planteamientos. Quizás la insurgencia, como respuesta a ese estado de las cosas que cada vez está más cercano a la desidia, sea necesaria y seguramente obligatoria ${ }^{23}$. 